\title{
Distribution of School Children Based on the Type of Terminal Plane in Primary Dentition: A Study among 3- to 5-year-old Children in Chennai, Tamil Nadu, India
}

\author{
Vijayakumar Anu' ${ }^{1}$, Bellamkonda Pavani ${ }^{2}$, Dornadula Pavani ${ }^{3}$, Beatrice JX Liana ${ }^{4}$, Firdose A Lubna ${ }^{5}$, Yalagala V Saikrishna ${ }^{6}$
}

\begin{abstract}
Background: This study was aimed to investigate the prevalence of primary malocclusion among school children under 5 years of age in Chennai, Tamil Nadu.

Materials and methods: A total of 814 school children under 5 years were selected from 5 government and 5 private schools in Chennai city, Tamil Nadu, India, and their occlusion was recorded based on the terminal planes. Data were analyzed using SPSS version 16 software. Frequency distribution and Chi-square test were carried out.

Results: The most common occlusion seen in the present study was flush terminal plane (54.05\%). Of them, $43.73 \%$ had mesial step and $2.08 \%$ had distal step. There was no significant difference between males and females.

Conclusion: The signs of future malocclusion are found to be high. Hence, early preventive and interceptive measures are necessary to reduce the prevalence of future developing malocclusion and further adverse effects.

Keywords: Dental occlusion, Distal step, Mesial step, Primary dentition, Primary malocclusion, Terminal plane. International Journal of Clinical Pediatric Dentistry (2020): 10.5005/jp-journals-10005-1722
\end{abstract}

\section{INTRODUCTION}

Childhood is the mirror that reflects the propensity of adulthood. Primary dentition is an indicator of potentially perfect permanent dentition. The function of primary dentition includes maintenance of the occlusion and space for the permanent dentition in addition to mastication. The primary dentition is complete with the eruption of the second primary molars, which means that the location for the eruption of the permanent teeth in the future has already been determined at this stage. ${ }^{1}$

Malocclusion is a condition that deflects from the normal relation of the teeth to the other teeth in the same arch and the teeth in the opposing arch. Malocclusion in primary dentition is classified based on terminal planes as follows: (1) flush terminal plane - the distal surfaces of the upper and lower second primary molars are in the same vertical plane in centric occlusion; (2) distal step-the distal surface of the lower second primary molar is more distal to that of the upper in centric occlusion; and (3) mesial step - the distal surface of the lower second primary molar is more mesial to that of the upper in centric occlusion., ${ }^{2,3}$ The terminal plane relationship is used as a guide to determine the future interocclusal relation of the erupting first permanent molars. While functionally insignificant at this time, this relationship can greatly influence the position of the first permanent molars later, as the eruption path of the first permanent molars is guided by the distal surface of the distal root and tooth crown of the second primary molar. ${ }^{1}$

Many studies ${ }^{4-6}$ were performed to know the prevalence of malocclusion among school children in India. Occlusion in primary dentition plays a major role in determining the occlusion of the permanent dentition. Hence, it is important to have a baseline data of primary malocclusion as future developing malocclusion can be prevented in earlier stage. Literature on the prevalence of primary malocclusion among school children in Chennai population
1,2,4-6 Department of Public Health Dentistry, Sathyabama University Dental College and Hospital, Chennai, Tamil Nadu, India

${ }^{3}$ Department of Conservative Dentistry and Endodontics, Sathyabama University Dental College and Hospital, Chennai, Tamil Nadu, India

Corresponding Author: Vijayakumar Anu, Department of Public Health Dentistry, Sathyabama University Dental College and Hospital, Chennai, Tamil Nadu, India, Phone: +91 7598478993, e-mail: pcnanu@gmail.com

How to cite this article: Anu V, Pavani B, Pavani $D$, et al. Distribution of School Children Based on the Type of Terminal Plane in Primary Dentition: A Study among 3- to 5-year-old Children in Chennai, Tamil Nadu, India. Int J Clin Pediatr Dent 2020;13(2):136-137.

Source of support: Nil

Conflict of interest: None

is scarce, and hence, this study was carried out to assess the prevalence of primary malocclusion based on the type of terminal planes among school-going children in Chennai city, Tamil Nadu.

\section{Materials and Methods}

\section{Study Area}

This study was conducted in Chennai, the capital of Tamil Nadu state in India, which is located on the Coromandel coast of the Bay of Bengal.

\section{Sample Size Estimation}

Sample size was estimated as to be 814 subjects using the formula $n=\left(z^{2} p q\right) / d^{2}$ where, " $n$ " is the desired size, " $z$ " the standard normal variant at a given confidence level (1.96) at $5 \%$ level of significance or $95 \%$ confidence level, " $p$ " the prevalence $(23 \%)$ obtained from a previous study conducted by Rao et al. ${ }^{7}$ and $q=1-p$ is the alternate proportion, and " $d$ " the acceptable error was set as 3 . 
Table 1: Comparison of prevalence of malocclusion between male and female

\begin{tabular}{lllll}
\hline & \multicolumn{3}{c}{ Malocclusion } \\
\cline { 2 - 5 } Gender & $\begin{array}{l}\text { Flush terminal } \\
\text { plane }\end{array}$ & Mesial step & Distal step & Total \\
\hline Male & $300(56.8 \%)$ & $214(40.53 \%)$ & $13(2.46 \%)$ & 528 \\
Female & $140(48.95 \%)$ & $142(49.65 \%)$ & $4(1.39 \%)$ & 286 \\
Total & $440(54.05 \%)$ & $356(43.73 \%)$ & $17(2.08 \%)$ & 814 \\
Chi-square value & 7.19 & & & \\
$p$ value & 0.066 & & & \\
\hline
\end{tabular}

\section{Sample Selection}

The study sample was selected randomly from 5 private schools and 5 government schools in Chennai. Children aged between 3 years and 5 years were included in the study. School children who had missing teeth, grossly decayed teeth, developmental anomalies, full restoration crowns in the posterior tooth, and any tooth with restoration in the proximal surfaces were excluded.

\section{Data Collection}

A cross-sectional study was conducted among school children under 5 years of age after obtaining ethical clearance from the Institutional Human Ethical Committee of Sathyabama Dental College, Chennai (Sathyabama University/lHEC/study no. 018). Permission was obtained from the school authorities. Parents of the school children were informed by the principals of the schools, and a written consent was obtained from the parents.

Type IV ADA clinical examination ${ }^{8}$ was carried out under natural light. The participants were made to sit on a chair and were asked to rinse their mouth thoroughly with water before the examination. The participants were made to bite in centric occlusion, and the occlusion was recorded based on the terminal planes. The primary malocclusion was recorded as flush terminal plane, when the distal surfaces of upper and lower second molars are in the vertical plane; mesial shift, when the distal surface of the lower second molar is mesial to the upper in centric occlusion; distal shift, when the distal surface of the lower second molar is distal to the upper in centric occlusion. ${ }^{2,3}$

A pilot study was conducted prior to the start of the study to calibrate the examiners, and the kappa value was estimated to be 94\%.

The data collected were entered in Windows Excel 2017, and statistical analysis was done using SPSS version 16 software. Since the data were not normally distributed, nonparametric tests were carried out. Frequency distribution and Chi-square tests were carried out. The level of significance was set at 0.05 .

\section{Results}

Among the total 814 children, 528 males and 286 females were examined and assessed for prevalence of different types of primary malocclusion. Table 1 shows that of the 814 population, 441 (54.1\%) exhibited flush terminal plane, mesial shift was seen in $43.7 \%$, and distal step in 17 (2.1\%), respectively.

It can also be elucidated from Table 1 that the flush terminal plane was found to be more prevalent in both males (56.8\%) and females. There is no statistical difference between primary malocclusion based on gender.

\section{Discussion}

Epidemiological studies to document the occlusion in primary dentition in various populations are important because primary occlusion determines the future occlusion and often reflect the need for preventive and interceptive orthodontic treatment. ${ }^{9}$

Bishara et al. ${ }^{10}$ conducted a study to describe the changes in the molar relationship from the deciduous dentition to the permanent dentition and reported that the cases $56 \%$ of cases with flush terminal plane turned to class I occlusion and $44 \%$ to class II occlusion. Children with distal step developed class II permanent malocclusion and recommended that the treatment should be started at an earlier stage as there is less chance of selfcorrection. Cases with mesial step developed class I permanent molar relationship; however, there are chances with class III molar relationship depending on the magnitude of the mesial step.

The present study was conducted to know the prevalence of primary malocclusion among the school-going children in Chennai, Tamil Nadu, as there is scarcity of literature in this population and to create an awareness about malocclusion thereby helping them to prevent the upcoming aftermath. From this study, it is observed that flush terminal plane (54.05\%) was the most prevalent type of primary malocclusion. Higher prevalence of mesial step (43.73\%) was also reported in the present study. The distal step is the least common in the present study (2.08\%). This is in accordance with Indian studies conducted by Hegde et al., ${ }^{4}$ Bhat et al., ${ }^{5}$ and Shavi et al. ${ }^{6}$

This study provided insights about the occlusion on primary malocclusion based on the terminal planes alone. There are other parameters that also determine the development of future malocclusion. This can be the limitation of the present study. Further longitudinal studies can be undertaken considering the various occlusal parameters to describe the changes from primary occlusion to permanent malocclusion in this population.

To conclude, the signs of future malocclusion is found to be high. Hence, early preventive and interceptive measures are necessary to reduce the prevalence of future developing malocclusion and further adverse effects.

\section{References}

1. Sriram CH, Priya VK, Sivakumar N, et al. Occlusion of primary dentition in preschool children of Chennai and Hyderabad: A comparative study. Contemp Clin Dent 2012;3(1):31. DOI: 10.4103/0976-237X.94543.

2. Moyers RE. Handbook of Orthodontics, 4th ed., Chicago, IL: Year Book Medical Publishers, Inc.; 1988. p. 577.

3. Forster TD. A Textbook of Orthodontics, 3rd ed. London, UK: Blackwell Scientific Publications; 1990. p. 55.

4. Hegde S, Panwar S, Bolar DR, et al. Characteristics of occlusion in primary dentition of preschool children of Udaipur, India. European journal of dentistry. 2012;6(1):51.

5. Bhat SS, Rao HA, Hegde KS, et al. Characteristics of primary dentition occlusion in preschool children: an epidemiological study. Int J Clin Pediatr Dent 2012;5(2):93-97. DOI: 10.5005/jp-journals-10005-1143.

6. Shavi GR, Hiremath NV, Shukla R, et al. Prevalence of spaced and non-spaced dentition and occlusal relationship of primary dentition and its relation to malocclusion in school children of Davangere. J Int Oral Health 2015;7(9):75-78.

7. Rao DB, Hegde AM, Munshi AK. Malocclusion and orthodontic treatment need of handicapped individuals in South Canara, India. Int Dent J 2003;53(1):13-18. DOI: 10.1111/j.1875-595X.2003.tb00650.x.

8. Peter S. Essentials of Public Health Dentistry. 5th ed., Survey procedures in dentistry. India: Arya; 2013. p. 391.

9. Mtaya M, Brudvik P, Åstrøm AN. Prevalence of malocclusion and its associated factors among pre-schoolchildren in Kinondoni and Temeke Districts, Tanzania. Tanzan J Health Res 2017;19(2):1-9.

10. Bishara SE, Hoppens BJ, Jakobsen JR, et al. Changes in the molar relationship between the deciduous and permanent dentitions: $A$ longitudinal study. Am J Orthod Dentofacial Orthop 1988;93(1):19-28. DOI: $10.1016 / 0889-5406(88) 90189-8$. 